\title{
Enormous Disfiguring Thyroid Swelling
}

\author{
Saurav Chakravartty $•$ Krishnendu Maiti
}

Received: 11 March 2009/Accepted: 30 March 2009/Published online: 17 November 2010

(C) Association of Surgeons of India 2010

\begin{abstract}
A 35 year old woman presented to us with a huge thyroid swelling $(17 \times 11 \times 14 \mathrm{~cm})$ in front of her neck which she had for the last 10 years. She was not toxic or dyspnoeic. It was multinodular with areas of firmness and cystic feeling. She had some degree of tracheal compression but no intra thoracic extension as confirmed by a CT scan of the neck. Endotracheal intubaton was done and she was operated on using a long transverse incision with division of the strap muscles for better exposure. She did not need a tracheostomy and the post operative period was uneventful. The histopathological revealed a goitre.
\end{abstract}

Keywords Huge goitre $\cdot$ Thyroid tracheal pressure

\section{The Case}

A 35 year old woman presented to us with a huge thyroid swelling $(17 \times 11 \times 14 \mathrm{~cm})$ in front of her neck which she had for the last 10 years. It had grown insidiously until a sudden spurt for the last year. She was not toxic and did not have dyspnoea or dysphagia. Apart from the obvious disfigurement her other problem was due to its enormous weight that caused a discomforting dragging sensation. It was multinodular with areas of firmness and cystic feeling. A CT scan of her neck revealed a well defined heterogeneously enhancing space occupying lesion $16.9 \times 11.2 \times 14.5 \mathrm{~cm}$ in size with flecks of calcification extending up to the angle of the mandible and below anterior to the sternum. There was no obvious intrathoracic extension. The proximal trachea was compressed and displaced to the right. Endotracheal intubaton although difficult, was successfully done. She was operated through a long transverse incision with division of the strap muscles for better exposure. The thyroid

S. Chakravartty $(\bowtie) \cdot$ K. Maiti

Department of Surgery, Medical College, Kolkata,

Kolkata, India

e-mail: saurav_tty@yahoo.com
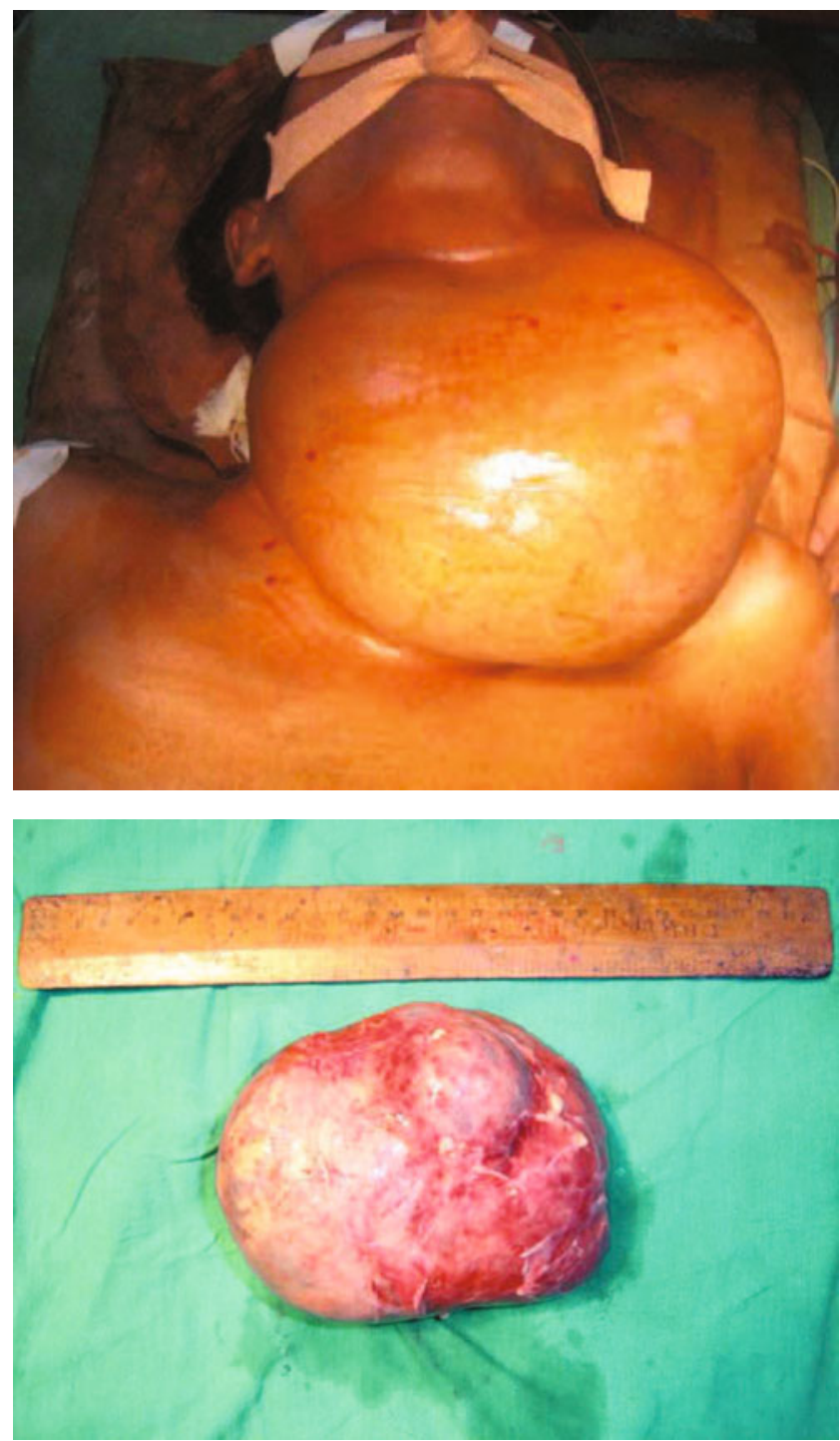

mass was excised. It was found to weigh about $3.5 \mathrm{kgs}$. She did not need a tracheostomy and the post operative period was uneventful. The histopathology revealed a colloid goitre. 